\title{
A relevância sociojurídica da função social da propriedade: reconhecimento de novas necessidades e ação integrada interinstitucional
}

\author{
The socio-legal relevance of the social function of property: recognition of new needs and integrated
}

inter-institutional action

La relevancia sociojurídica de la función social de la propiedad: reconocimiento de nuevas necesidades y acción interinstitucional integrada

Recebido: 28/07/2021 | Revisado: 02/08/2021 | Aceito: 09/08/2021 | Publicado: 13/08/2021

\author{
Murilo Mendonça Barra \\ ORCID: https://orcid.org/0000-0002-8664-4274 \\ Pontifícia Universidade Católica, Brasil \\ E-mail: murilombarra@gmail.com \\ Lúcia Maria de Moraes \\ ORCID: https://orcid.org/0000-0002-9459-3948 \\ Pontifícia Universidade Católica, Brasil \\ E-mail: luciadhescmoradia@gmail.com
}

\begin{abstract}
Resumo
Política urbana é o conjunto de providências que objetivam ordenar os espaços habitáveis, organizando todas as áreas em que o ser humano exerce atividades sociais e toda propriedade, sem exceção, respeitando o direito do proprietário, deve cumprir sua função social. A maioria dos municípios do estado de Goiás enfrenta o problema do crescimento urbano informal com construções irregulares e assentamentos ilegais, por exemplo. Em Goiás, foi criado o programa permanente de regularização fundiária com o objetivo de legalizar as áreas ocupadas irregularmente "Casa Legal". Este artigo é um estudo de caso de base qualitativa, que analisa a implementação do programa no Bairro Parque das Brisas, no município de Caldas Novas-GO, no qual foi adotada a política de regularização fundiária de interesse social com o objetivo de doar o título de propriedade aos seus moradores por meio do processo de legalização das áreas de interesse social. Os resultados apontam que, quando há a integração de interesses entre o público e o privado, o ordenamento jurídico determina a proibição do uso abusivo da propriedade. O processo se deu com abordagens específicas, integrados e complementares entre si, envolvendo aspectos inter/multidisciplinares como fundiário, pesquisa de documentos de existência da gleba, cadeia sucessória, plantas e cadastros existentes, a fim de possibilitar a titulação da terra.
\end{abstract}

Palavras-chave: Sociedade; Regularização fundiária; Função social da propriedade.

\begin{abstract}
Urban policy is the set of measures that aim to organize living spaces, organizing all areas in which human beings carry out social activities and all property, without exception, respecting the owner's right, must fulfill its social function. Most municipalities in the state of Goiás face the problem of informal urban growth with irregular constructions and illegal settlements, for example. In Goiás, the permanent land regularization program was created with the objective of legalizing illegally occupied areas "Casa Legal". This article is a qualitative-based case study that analyzes the implementation of the program in Parque das Brisas in Caldas Novas' municipality of GO, where the policy of land regularization of social interest was adopted in order to donate property titles to its residents through the process of legalizing areas of social interest. Results show when there is an integration of public and private interests, the legal system can determine prohibition of abusive use of property. The process took place with specific approaches, integrated and complementary to each other, involving inter/multidisciplinary aspects such as land tenure, search for documents of existence of the land, succession chain, existing plants and records, in order to enable land titling.
\end{abstract}

Keywords: Society; Land regularization; Social function of property.

\section{Resumen}

La política urbana es el conjunto de medidas que tienen como objetivo organizar los espacios de vida, organizando todos los ámbitos en los que el ser humano desarrolla actividades sociales y toda propiedad, sin excepción, respetando el derecho de propiedad, debe cumplir su función social. La mayoría de los municipios del estado de Goiás enfrentan el problema del crecimiento urbano informal con construcciones irregulares y asentamientos ilegales, por ejemplo. En Goiás, se creó el programa de regularización permanente de tierras con el objetivo de legalizar las áreas ocupadas ilegalmente "Casa Legal". Este artículo es un caso de estudio de base cualitativa que analiza la implementación del programa en Bairro Parque das Brisas, en el municipio de Caldas Novas-GO, en el cual se adoptó la política de 
regularización de tierras de interés social para la donación del título de propiedad. a sus vecinos a través del proceso de legalización de áreas de interés social. Los resultados muestran que, cuando hay una integración de intereses entre lo público y lo privado, el ordenamiento jurídico determina la prohibición del uso abusivo de la propiedad. El proceso se desarrolló con enfoques específicos, integrados y complementarios entre sí, involucrando aspectos inter / multidisciplinarios como la tenencia de la tierra, búsqueda de documentos sobre la existencia de la tierra, cadena de sucesión, plantas y registros existentes, para posibilitar la titulación de la tierra.

Palabras clave: Sociedad; Regularización de tierras; Función social de la propiedad.

\section{Introdução}

No século XXI, a maioria das políticas públicas teve como objetivo a produção de moradias para classes de renda média e baixa. A Constituição Federal de 1988 prevê a criação de políticas públicas habitacionais objetivando a intervenção em edifícios ociosos em áreas centrais, porque edifícios ociosos impedem que o imóvel cumpra plenamente sua "função social da propriedade", função essa definida pela Emenda Constitucional de Iniciativa Popular pela Reforma Urbana (Anitelli \& Tramontano, 2016). Essa função social se institui no princípio básico que direciona todas as políticas públicas de urbanização, como o Estatuto das Cidades e os Planos Diretores (Bassul, 2002).

O estado de Goiás sofreu reflexos da migração do meio rural para o meio urbano, a ocupação populacional foi lenta e diversificada, transformando a região centro-oeste em um polo atrativo de desenvolvimento econômico a partir da década de 1960. Com a transferência da capital do país, Brasília, para a região, o estado atraiu contingente migratório apresentando crescimento demográfico, o que propicia problemas urbanísticos, principalmente os relacionados à habitação popular e às consequentes implicações sociais de moradia e do uso das cidades como espaço de convívio e vivência.

A interiorização do povoamento se deu na posse de terras, possibilitando a ocupação de grandes áreas, legada a pequenos grupos das elites possuidoras de escravos. A Lei $n^{\circ}$ 601/1850 - Lei de Terras - foi uma das primeiras legislações sobre normas do direito agrário brasileiro, sendo uma legislação específica para a questão fundiária. Sua valorização impulsionava o interesse pela regularização da propriedade fundiária. Por outro lado, esse processo era caro, e a situação irregular possibilitava a incorporação de novas terras, modificando a estrutura agrária de forma concentrada com poucas famílias assegurando o controle das terras favorecendo os donos das mesmas e não aos escravos que ali trabalhavam (Gonçalves, 2018; Junior S; Vale; Wander, 2016).

Com a abolição da escravatura, as cidades não estavam preparadas para receber esse contingente populacional, dando lugar ao surgimento de ocupações de terra e formação de favelas como forma da moradia de população de baixa renda. Battaus \& Oliveira (2016) relatam que a irregularidade fundiária é um processo comum nas cidades brasileiras, fruto do crescimento urbano desordenado e de falta de políticas públicas de habitação que se pautam na equalização das desigualdades sociais do acesso a proteção concernente a moradia.

A maioria dos municípios do Estado de Goiás, na ausência de uma política urbana, lida com as consequências do desenvolvimento urbano informal, que podem ser: terrenos ocupados, loteamentos clandestinos, formação de favelas, construções irregulares e assentamentos ilegais invadindo a paisagem dos municípios.

Battaus \& Oliveira (2016) definem a política urbana como o conjunto de providências que objetivam ordenar os espaços habitáveis, organizando todas as áreas em que o ser humano exerce funções sociais indispensáveis à sua sobrevivência, isto é, habitação, trabalho, lazer e circulação. Visa, a um só tempo, proporcionar melhoria das condições de vida do homem na comunidade. A política urbana no Brasil foi contemplada no Capítulo II, nos artigos 182 e 183 da Constituição de 1988. Ainda no artigo $5^{\text {a }}$, inciso XXIV, da Carta Magna está estabelecido o procedimento para desapropriação por necessidade ou utilidade pública, ou por interesse social, mediante justa e prévia indenização em dinheiro.

Cabe destacar que os princípios constitucionais foram regulamentados por meio de políticas públicas previstas na Lei 10.257/2001 - o Estatuto da Cidade, que tem por instrumentos, elencados por Bassul (2002): a gestão democrática da política 
urbana; o parcelamento edificação ou utilização compulsória de terrenos; IPTU progressivo no tempo; desapropriação com pagamento em títulos da dívida pública; usucapião especial; concessão de uso especial para fins de moradia; direito de superfície; direito de preempção; outorga onerosa do direito de construir e de alteração do uso; operaçães urbanas consorciadas; transferência do direito de construir; estudo de impacto de vizinhança; e consórcio imobiliário.

Para Vieira \& Júnior (2014), os assentamentos apresentam três tipos de irregularidade fundiária: a) irregularidade dominial, quando o possuidor ocupa uma terra pública ou privada, sem qualquer título que lhe dê garantia jurídica sobre essa posse; b) urbanística e c) ambiental. Nos últimos dois casos, quando o parcelamento não está de acordo com a legislação urbanística e/ou ambiental e não foi devidamente licenciado. Partindo disso, o governo iniciou uma atuação direcionada aos moradores com baixa renda, que se encontram em situação de segregação e isolamento social, em especial, dessas comunidades.

A escritura formaliza a venda e cria um título hábil à transmissão da propriedade do imóvel e o registro transfere definitivamente a titularidade do imóvel ao comprador e com ela, todas as obrigações acessórias. A escritura pública é necessária para dar validade formal ao ato jurídico exigido por lei, sendo que o ato jurídico pode ser uma compra/venda; uma doação; uma simples declaração, proporcionando maior segurança jurídica às pessoas que a formalizam no Cartório de Tabelionato de Notas do seu município (Alonso Freire Chryssocheris, 2017).

A Lei Federal n ${ }^{\circ}$ 11.977/2009 definiu dois tipos básicos de regularização fundiária para dar conta dessas situações: regularização fundiária de interesse social e de interesse específico. A Lei Estadual $\mathrm{n}^{\circ}$. 17.545/2012 dispõe sobre a regularização de ocupação de imóveis urbanos de domínio do estado de Goiás e dá outras providências. O capítulo II dessa lei relata sobre a regularização fundiária que faz por meio da doação conforme com as condições do artigo $6^{\circ}$ (GOIÁS, 2012).

Com o propósito de solucionar as ocupações ${ }^{1}$ irregulares em áreas de domínio do Estado, o estado de Goiás formulou em 2011 o programa permanente de regularização fundiária chamado "Casa Legal - sua escritura na mão". Vieira \& Junior (2014) conceituam essa regularização como o processo que inclui medidas jurídicas, urbanísticas, ambientais e sociais, com a finalidade de integrar assentamentos irregulares ao contexto legal das cidades.

Segundo esse contexto, o Programa "Casa Legal" tomou por base em um amplo pacto social pela legalização das edificações (habitações) urbanas, envolvendo órgãos governamentais das esferas estaduais e municipais, Ministério Público Estadual, Corregedoria Geral de Justiça, cartórios e comunidade atendida. A partir da consolidação dessa rede de parcerias, o programa foi implementado em diversas cidades, superando entraves legais, burocráticos e políticos, a exemplo do Bairro Parque das Brisas em Caldas Novas.

O presente trabalho consiste em um estudo exploratório de caráter qualitativo (Cresswell, 2007), que aborda a descrição das experiencias a partir da realidade local, trazendo em seu escopo a compreensão e relatos dos próprios participantes do processo de implementação, sendo também caracterizado como um estudo de caso único (YIN, 2015), considerando sua relevância ímpar, sem outro elemento de comparação, tendo em vista a análise em profundidade do processo executado. Foram usados na análise documentos públicos da Agência Goiana de Habitação (AGEHAB) órgão público responsável pela implementação da política habitacional no estado. O recorte é longitudinal, sendo definido o período de implementação da política, ou seja, o ano de 2017.

O objetivo geral do trabalho foi descrever os processos de implementação da política pública em Goiás "Casa Legal" a partir da realidade local, relatando os dilemas, as lacunas de implementação, bem como os resultados obtidos na implementação. Para isso, também como objetivos específicos visamos apresentar a importância e relevância social da articulação interinstitucional, regulamentação da regularização fundiária, área física alvo de processo de reintegração de posse

${ }^{1}$ Áreas ocupadas são residências ocupadas por moradores que possuem a posse, mas não possuem o direito da propriedade. 
tendo como referência a intervenção nas relações sociais submetendo-se ao princípio da função social da propriedade privada e intervenções legais considerando a legitimidade e melhoria da qualidade de vida frente à estrutura econômica e social apresentada a partir do estudo técnico e social desenvolvido com a comunidade local.

\section{Metodologia}

A metodologia escolhida para este estudo é a qualitativa, e lança mão de estudo de caso (Yin, 2015), com o uso de documentos institucionais produzidos pelos órgãos envolvidos na implementação do programa no bairro Parque das Brisas em Caldas Novas/GO. Ademais, será utilizado como principal técnica a descrição dos processos de implementação previstos segundo a legislação específica quanto a regularização fundiária, já mencionadas, além dos critérios técnicos escolhidos pelas equipes dos órgãos para a seleção da população ao qual a política impactou, denotando a relevância do caso escolhido.

\subsection{Região de abrangência}

A região de estudo foi o Bairro Parque das Brisas, antiga Vila de Furnas, localizado no município de Caldas Novas, estado de Goiás, cidade turística conhecida pelos seus rios de águas quentes. De acordo com IBGE (2020), Caldas Novas tem uma população estimada de 84.900, área da unidade territorial até 2016 foi de 1.608,439 km². Segundo Sousa, Peres e Martins (2017) é um dos 21 municípios da Microrregião Geográfica de Meia Ponte, no Sul de Goiás, entre as coordenadas $17^{\circ}$ e $28^{\prime}$ e $18^{\circ}$ e $05^{\prime}$ de latitude Sul e $48^{\circ}$ e $27^{\prime}$ a $48^{\circ}$ e $56^{\prime}$ de longitude Oeste, com sua altitude variando entre 520 e 1043 metros, distando apenas 170 km de Goiânia.

\subsection{Procedimentos para regularização fundiária pela AGEHAB}

O tipo de regularização fundiária adotada foi a de interesse social, princípio da política de legalização das ocupações de imóveis urbanos nas cidades goianas. Esse trabalho foi coordenado e desenvolvido pela Agência Goiana de Habitação S/A AGEHAB, que realizou levantamentos topográficos de áreas de imóveis registrados como "glebas".

Define-se como "gleba" como a porção de terra que não tenha sido submetida, que jamais foi loteada ou desmembrada sob a vigência da nova lei, gleba é a terra crua, sem qualquer regulamentação e adequação às leis brasileiras e regionais (Amadei \& Amadei, 2014).

Depois foi elaborado o projeto urbanístico, enviado à prefeitura de Caldas Novas. A agência acompanhou a emissão e aprovação do Decreto ${ }^{2}$ realizada pela prefeitura que analisou a planta urbanística do loteamento urbano e posterior registro do parcelamento das áreas.

Um debate envolvendo técnicos e gestores foi necessário até culminar com a edição dos decretos de parcelamento das áreas. Com os decretos, a AGEHAB pôde efetuar o cadastramento das famílias para a escrituração do imóvel e emissão dos títulos de propriedade dos imóveis.

Nessa etapa do processo, houve participação ativa da Corregedoria de Justiça e Procuradoria Geral do Estado (PGE), auxiliando na confecção dos títulos quanto no acompanhamento, juntamente aos cartórios de registro de imóveis. Na etapa seguinte a equipe da AGEHAB vinculada ao programa Casa Legal compareceu ao bairro coletando as assinaturas dos beneficiários na escritura. De acordo com AGEHAB (2017), o processo foi totalmente custeado pelo Estado no caso das famílias originárias ou com renda de até quatro salários mínimos, receberam a escritura gratuita. As escrituras são o instrumento legal para que as famílias possam certificar a propriedade de suas moradias.

\footnotetext{
${ }^{2} \mathrm{O}$ decreto consiste no reconhecimento do parcelamento de uma gleba, possibilitando a emissão do documento da área objeto de parcelamento (lotes), de forma individualizada.
} 
Os documentos escriturais foram encaminhados ao cartório, para lavratura, registro e autenticação das escrituras. Depois da realização de todos os procedimentos os títulos de propriedade foram entregues aos beneficiários.

$\mathrm{Na}$ atualidade, a política habitacional em Goiás é executada pela AGEHAB que atende a parcela da população, que não possui condições de adquirir um imóvel por meio do mercado imobiliário formal, o que leva a busca pela inserção em Programa de Habitação de Interesse Social, à procura do acesso ao direito de uma moradia que lhe garanta o direito a cidade com dignidade (Oliveira e Silva Costa, 2016).

Quanto aos programas de habitação promovidos que Goiás implementa, podemos elencar: o programa Morada Nova, como alternativa a questão habitacional, cuja implementação ocorre por meio da concessão do Cheque Moradia, cujo objetivo é a redução do déficit habitacional, com a construção de moradias, reformas e melhorias em habitações existentes. Além disso, por meio das parcerias com o Governo Federal, o órgão gestor estadual procura captar recursos do Orçamento Geral da União (OGU) e do Fundo de Garantia do Tempo de Serviço (FGTS), de responsabilidade da Caixa Econômica Federal de Goiás (CEF), com a intenção de efetivar os projetos (Oliveira e Silva Costa, 2016).

\subsection{Regularização do bairro Parque das Brisas}

No dia 20/07/2016 foi realizada uma reunião para tratar da questão da reintegração de posse no município de Caldas Novas/GO, sob a presidência, Juiz auxiliar e membro do Comitê de Monitoramento de Conflitos Fundiários. Autoridades e representante dos moradores participaram desta reunião, como a Procuradora Geral do Município de Caldas Novas/GO, representante da AGEHAB e de FURNAS, coordenador de Direito Ambiental e Fundiário de Furnas, Gestor de Patrimônio de Furnas, Secretaria Municipal de Habitação da cidade de Caldas Novas/GO; representante dos moradores; Superintendente Executivo de Administração Penitenciária/Responsável pela Presidência da Comissão de Conflitos Fundiários, membro do Comitê de Monitoramento de Conflitos Fundiários.

A Comissão de Conflitos Fundiários encaminhou ofício aos juízes condutores da reintegração de posse, pleiteando a suspensão dos prazos processuais das demandas referentes aos moradores da vila residencial e oficiaria. A AGEHAB apresentou a demanda ao Ministério das Minas e Energia, visando buscar uma solução pacifica para o conflito instalado, observando, principalmente, a questão social das famílias sem moradia.

Foi entregue para a Gerente de Responsabilidade Sociocultural de Furnas o relatório socioeconômico das famílias residentes no Bairro Parque das Brisas, demonstrando a situação de extrema vulnerabilidade das famílias, sendo que as mesmas se enquadravam nos critérios da Lei Estadual n. ${ }^{\circ}$ 17.545/2012 que define os critérios de doação de moradias populares.

A Diretoria de Furnas em reunião com a AGEHAB manifestou-se favorável a doação para as famílias que se enquadrassem no perfil. Em seguida, a AGEHAB e em parceria com a empresa Furnas - Centrais Elétricas, iniciaram a urbanização e regularização fundiária regional dos assentamentos precários existentes no bairro Parque das Brisas, com um público de 23 famílias residentes em lotes irregulares. Considerando que à época, encontrava-se em construção a primeira usina telecomandada - Usina de Corumbá, situada no rio Corumbá, distante cerca de $30 \mathrm{~km}$ da cidade de Caldas Novas (GO), essa usina tem potência instalada de $375 \mathrm{MW}$, dividida em três unidades geradoras (Furnas, 2021). Além disso, durante a construção da usina, a empresa criou um centro de informações para esclarecimentos quanto ao empreendimento e aos programas ambientais do empreendimento.

O processo abrangeu aspectos com abordagens específicas, integrados e complementares entre si, envolvendo aspectos inter e multidisciplinares como fundiário, pesquisa de documentos de existência da gleba, cadeia sucessória, plantas e cadastros existentes, a fim de possibilitar a titulação da terra. No aspecto administrativo e fiscal está relacionado à inclusão das 
áreas regularizadas nos cadastros imobiliários e no planejamento municipal, promovendo assim, suas atualizações para projetos urbanos da cidade.

Os projetos consideraram os seguintes aspectos: a) aspecto regulamentar, que diz respeito às certidões e averbações dos imóveis em cartórios; b) aspecto operacional comunitário, concernente às campanhas elucidativas e de envolvimento da população no processo de regularização, com a participação dos moradores no processo de organização comunitária e, c) aspecto social, relacionado à promoção humana, capaz de fixar os ocupantes na terra.

\subsection{Caracterização Socioeconômica das famílias}

A análise socioeconômica foi realizada pela equipe multidisciplinar da AGEHAB que realizou visitas técnica e social, no mês de julho de 2017, para averiguação da situação cadastral das 23 famílias residentes no bairro, incluindo o acompanhamento da equipe técnica de Furnas. A vistoria técnica teve embasamento legal em documentos oficiais emitidos pela AGEHAB, que continham a lista dos titulares dos imóveis alvos de intervenção de regularização fundiária, partindo do primeiro levantamento situacional, realizado em outubro de 2016.

Nessa vistoria foi utilizado o mapa oficial da empresa, elaborado em 2016. Assim, foi possível detectar alterações nos endereços originários, cabendo à equipe técnica o ajustamento para a correta intervenção de regularidade física junto a Furnas, detentora da posse da área em estudo. O principal motivo de ajustes de intervenção diz respeito à doação oficial da referida área, pertencente legalmente a Furnas, e que foi feito considerando o alto nível de vulnerabilidade social das famílias posseiras residentes.

\subsection{Intervenção Estatal e Jurídica nos processos de Regularização Fundiária}

A Diretoria de Desenvolvimento Institucional e Cooperação Técnica da AGEHAB, sediada em Goiânia, compareceu à Caldas Novas para visitar as famílias in loco, afim de comprovar a situação de vulnerabilidade social, reunindo com o Promotor de Justiça da comarca para tratar da regularização. Foram realizadas reuniões técnicas com as autoridades de Furnas e com a diretora da Secretaria Municipal de Habitação da cidade de Caldas Novas/GO. Foram realizados, por parte da AGEHAB, vários pleitos junto aos Juízes de Direito das ações de Reintegração de Posse, no sentido de ajudar a solucionar a questão. A reintegração de posse só é cabível quando houver esbulho, isto é, quando o possuidor é injustamente desapossado da coisa por um terceiro. Para tanto é imprescindível reforçar a explicação de "esbulho". Este é um ato pelo qual o possuidor se vê privado da posse mediante o emprego de violência, clandestinidade ou por abuso de confiança, vindo a perder a posse contra sua vontade. Essa é a mais grave das ofensas contra a posse, pois nela retira-se todo o poder de possuidor tornando impossível a continuidade do exercício de posse (Fonseca e Herek, 2017).

\section{Resultados e Discussão}

A AGEHAB, enquanto órgão gestor, coordena o processo com a implementação da política de regularização fundiária de interesse social no Estado de Goiás. Para que a política se efetive, o órgão realizou ações de formulação do desenho e implementação da política. A primeira ação foi a reformulação da Lei 17.545/2012 que dispunha sobre a regularização de ocupação de imóveis urbanos de domínio do Estado de Goiás.

Segundo essa normativa, o Poder Executivo autoriza a regularização das ocupações de imóveis urbanos de domínio do estado de Goiás, enquadrando nessas as ocupações de famílias de baixa renda. Conforme o artigo $2^{\circ}$, compreende a regularização fundiária de interesse social, nos seguintes casos: conjuntos habitacionais ou assentamentos de famílias carentes consolidados; áreas declaradas de interesse social para a implantação do projeto de regularização; áreas desapropriadas pelo Estado para fins de regularização e de áreas definidas em plano diretor como de especial interesse social (GOIÁS, 2012). 
Após os cadastramentos das famílias e emissão dos títulos de propriedades dos imóveis, identificou-se no estado de Goiás um passivo de 47.985 imóveis de propriedade do Estado que enquadra dentro do programa de regularização. Dessas, 19.211 escrituras registradas em cartório foram entregues de forma gratuita e 28.774 encontraram-se em processo de regularização fundiária distribuídas em várias etapas. O Programa está presente em mais de 50 municípios goianos para concluir a regularização desses imóveis, em mais de 100 bairros.

Existem ainda situações em que o processo de reintegração de posse tramita, sendo revertido pelo Estado, de modo que o interesse social sobrepôs uma decisão judicial, como na situação envolvendo a Usina de Furnas. Apesar da inovação que trouxe, a modernização da usina ocasionou problemas de ordem social para as famílias que moravam na Vila de Furnas à época de sua construção. O impasse dos moradores era antigo. O bairro foi criado há mais de 20 anos, por Furnas. A empresa pública é vinculada à Eletrobrás e ao Ministério de Minas e Energia, responsável pela construção da usina hidrelétrica de Corumbá.

A maioria das famílias não moram mais nas casas que são propriedades da empresa. As residências foram vendidas pelos próprios trabalhadores, ou invadidas por outras pessoas. A grande maioria foi embora, sendo que várias famílias permaneceram morando nas casas da Antiga Vila de Furnas, hoje Parque das Brisas, e 23 famílias delas são objeto de ações de desapropriação.

Conforme preconiza o Estatuto da Cidade, a desapropriação é um instrumento de política pública relacionados aos institutos jurídico e político. Considerando que a má utilização e/ou não utilização do imóvel causam inquietação social, gerando conflitos existenciais sociais. O princípio da função social da propriedade combinado com o processo de desapropriação para fins sociais, motivaram a atuação a efetivar a utilidade social do bem, em parceria com Furnas Centrais Elétricas.

Os moradores procuraram a AGEHAB, para que intervisse junto a Furnas para buscar uma solução que não viesse a desalojar os moradores que permaneceram no local. Conforme a Lei Estadual 17.545/2012, o Poder Executivo autoriza a regularizar as áreas desapropriadas pelo Estado para fins de regularização, sendo que uma das formas de regularização pode utilizar o instrumento como doação (Brasil, 2012).

Conforme o relatório socioeconômico realizado pela AGEHAB, das 23 famílias residentes no Parque das Brisas em Caldas Novas/GO, 19 famílias encontravam-se em situação de extrema vulnerabilidade social, necessitando que Furnas fizesse a doação dos referidos lotes às famílias cadastradas, evitando desta forma que houvesse desalojamento das famílias que ali fixaram moradia e não tinham outro local para estabelecerem residência, o que causaria um impacto social e até mobilização da opinião pública. Duas ações de reintegração de posse foram paralisadas devido ao intenso trabalho de todas as pessoas envolvidas em resolver a situação das famílias residentes no Bairro.

\subsection{Intervenção Política do Senado Federal}

Além das intervenções técnicas, judiciais e administrativas, a intervenção política do Senado Federal também foi necessária para encaminhar a questão para resolver a situação das famílias residentes no Bairro Parque das Brisas, que por sua complexidade demandaria tempo e boa vontade institucional para ser resolvida. A Senadora Lúcia Vânia, sensível a necessidades das famílias interviu junto ao Ministro de Minas e Energia na época, Fernando Coelho Filho, que em audiência com representantes da AGEHAB, município, e moradores comprometeram a buscar uma resolução rápida e definitiva desta situação.

Visando combater este quadro, uma das formas de intervenção do Estado para transformar a estrutura fundiária, com vistas à promoção da cidadania e melhoria da qualidade de vida da população, foi regularizar as ocupações existentes, com o desafio de minimizar a exclusão social e econômica dos moradores das áreas urbanas ou de expansão urbana ocupada. A 
regularização fundiária de interesse social é aplicável a assentamentos irregulares ocupados por população de baixa renda em que a garantia do direito constitucional à moradia justifica que se apliquem instrumentos, procedimentos e requisitos técnicos especiais (Vieira \& Junior, 2014).

Nesse sentido, a regularização fundiária dos assentamentos urbanos ocupados pela população de baixa renda se apresenta como uma das soluções encontradas para a inclusão sócio espacial da grande parcela dos moradores. Significa transformar a posse de determinada área em propriedade com endereço, identidade, acesso a serviço de infraestrutura, equipamentos coletivos, participação social nos processos de gestão e educação ambiental, e não apenas o reconhecimento da segurança individual da posse para os ocupantes.

Em relação a caracterização socioeconômica das famílias alvo de intervenção, foi detectado que nem todos os moradores estavam de acordo com os critérios previstos para a legalização da área, posto que, a unidade habitacional deve ter finalidade de moradia. Por esse motivo, algumas unidades não estavam em consonância com os parâmetros estabelecidos pela Lei Estadual n $17.545 / 2012$ seja por motivos de locação de uso comercial ou por não localização da família moradora.

A Lei Federal n $n^{\circ} 11.977$, de 07 de julho de 2009, define no art. 46 a regularização fundiária como o conjunto de medidas jurídicas, urbanísticas, ambientais e sociais que visam à regularização de assentamentos irregulares e à titulação de seus ocupantes, de modo a garantir o direito social à moradia, o pleno desenvolvimento das funções sociais da propriedade urbana e o direito ao meio ambiente ecologicamente equilibrado (Vieira e Junior, 2014).

Considerando as informações expressas nos cadastros e entendendo ser de responsabilidade do titular a veracidade dos dados, foi possível identificar suscintamente o perfil sócio econômico das famílias envolvidas no processo quanto aos principais aspectos. Entretanto, para quantificar os dados sociais, dos 23 cadastros foram utilizados apenas os 19 considerados válidos, a partir da legislação vigente. As demais quatro famílias não poderiam ser contempladas com o documento de regularidade por não atenderem os critérios básicos de elegibilidade pela Lei Estadual de Regularização Fundiária.

\subsection{Dados Socioeconômicos}

Em relação aos dados socioeconômicos e no que se refere à renda familiar, observou-se que $80 \%$ do grupo em análise possuía renda inferior a dois salários mínimos, denotando uma conjuntura financeira desfavorável, não permitindo uma reestruturação em caso de perda de um bem vital para o ser humano, no caso a moradia.

Conforme a Lei federal n. ${ }^{\circ} 11.977$ no artigo 47 relata que a regularização fundiária de assentamentos urbanos de interesse social, na qual define como assentamentos irregulares ocupados, predominantemente, por população de baixa renda, nos seguintes casos: área esteja ocupada, de forma mansa e pacífica, pelo menos cinco anos; imóveis situados em Zona Especial de Interesse Social; áreas da União, dos Estados, do Distrito Federal e dos Municípios declaradas de interesse para implantação de projetos de regularização fundiária de interesse social (Vieira \& Junior, 2014).

Com relação ao tempo de moradia, ressaltou-se que a maioria dos titulares estabeleceu tempo superior a cinco anos no bairro Parque das Brisas, desse modo apresentando um dos casos de assentamento irregular ocupado, conforme a lei federal $\mathrm{n}^{\circ}$ 11.977. Esse dado evidencia que, durante esse período, as famílias estabeleceram vínculos sociais, organizativos, ambientais e culturais, estruturando, suas vidas nessa localidade.

Conforme descrito no Gráfico 1, as ocupações profissionais não são muito diversas. Há apenas quatro variações, sendo estes: $21 \%$ de aposentados, $21 \%$ de pessoas que não trabalham fora, $16 \%$ de desempregados e por fim com a maior porcentagem para os trabalhadores autônomos diversos com um percentual de $42 \%$. De acordo com os dados levantados, foi possível inferir que o grupo de famílias envolvidas no processo apresenta perfil socioeconômico de relativa vulnerabilidade social, acentuada principalmente pela renda e pelas baixas perspectivas, apontadas nas ocupações profissionais. 
Gráfico 1 - Ocupações profissionais.

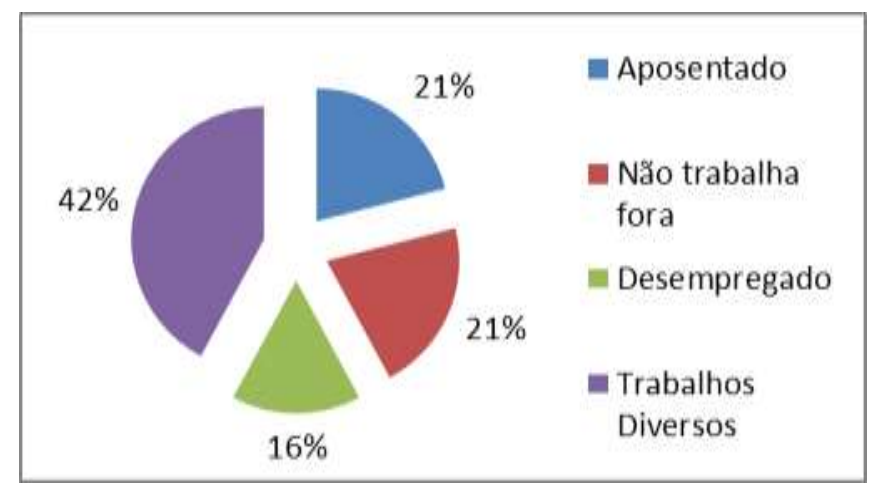

Fonte: Cadastro Técnico-Social da AGEHAB (2017).

Outro relevante fator social foi a composição dos núcleos familiares, especificamente quanto à existência de dependentes, onde existem mais de 50\% de famílias com dependentes.

Gráfico 2 - Percentual de Famílias por quantidade de dependentes.

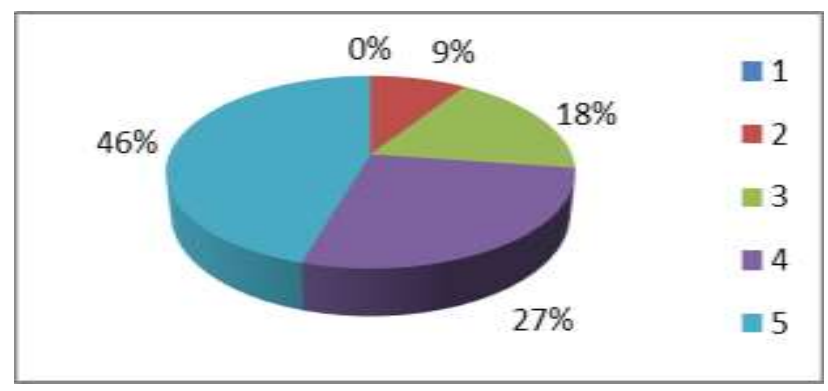

Fonte: Cadastro Técnico-Social da AGEHAB (2017).

Diante do grande número de habitações irregulares e precariedade habitacional nos espaços urbanos, o Brasil regulamentou os princípios do direito à moradia digna e da política de regularização fundiária colocando em questão a função social da propriedade urbana, sendo estes, norteadores da política urbana brasileira encontrada na Constituição Federal (CF) de 1988, nos artigos 182 e 183. Conforme a lei $10.257,10$ de julho de 2001 , o artigo $2^{\circ}$ relata que a política urbana tem por objetivo ordenar o pleno desenvolvimento das funções sociais da cidade e da propriedade urbana por meio de suas diretrizes (BRASIL, 2001).

Desse modo, a AGEHAB empenhada em promover o cumprimento da função social da terra entende que, empreender esforços no sentido de regularizar a situação das moradias das famílias envolvidas nesse processo foi o de garantir um direito essencial para os moradores do bairro Parque das Brisas, localizada em Caldas Novas. Uma das diretrizes da ordenação para o desenvolvimento social foi a regularização fundiária e urbanização de áreas ocupadas por população de baixa renda mediante o estabelecimento de normas especiais de urbanização, uso e ocupação do solo e edificação, considerados a situação socioeconômica da população e as normas ambientais.

\subsection{Intervenção Estatal e Jurídica nos processos de Regularização Fundiária}

A intervenção crescente do Estado na propriedade privada, não se reserva a não regulamentação do regime jurídico social da propriedade. Portanto, os instrumentais eficazes de proteção do direito fundamental à propriedade, no caso do bairro Parque das Brisas, município de Caldas Novas/GO, foram utilizados para efetivação das medidas legais cabíveis, considerando a situação de vulnerabilidade social das famílias ocupantes do terreno em questão. 
Uma vez que, na perspectiva humanitária, a regularização fundiária é um importante instrumento de política urbana, que deve ser promovida para assegurar o uso e a ocupação do solo adequado às necessidades de moradia digna dos moradores. "Tem por finalidade combater a desigualdade social e melhorar as condições de vida da população dos assentamentos precários" (Vieira e Junior, 2014).

A atuação jurídico-legal-institucional ocorrida na área de intervenção, junto com representantes das famílias, partiu do princípio da legalidade do pleito de regularização fundiária e teve como parceira efetiva o Comitê Estadual para Monitoramento e Resolução de Conflitos Fundiários Rurais e Urbanos (Decreto Judiciário n. ${ }^{\circ}$ 827/2015) e a Comissão de Conflitos Fundiários do Estado de Goiás.

Com pleito da suspensão dos prazos processuais das demandas referentes aos moradores do bairro, oficiando ainda o Ministério das Minas e Energia, para demonstrar a intenção do Estado de Goiás, por meio da AGEHAB, em buscar uma solução pacífica para o problema das famílias, observando, principalmente, a questão social e sustentável local.

Em resposta à demanda existencial de direito social da propriedade, Furnas - Centrais Elétricas manifestou-se favorável à doação do terreno ocupado pelas famílias que se enquadraram nas exigências contidas da Lei n. ${ }^{\circ}$ 17.545/2012. Conforme BRASIL (2012), uma das exigências constando nessa lei sobre a doação foi tratar-se de imóvel utilizado para finalidade residencial; o beneficiário ou qualquer membro da entidade familiar não era proprietário, concessionário ou possuidor de outro imóvel urbano ou rural e nem beneficiário de outro programa habitacional.

Para a concretização desta doação, foi necessário que o Ministério Público do Estado de Goiás concordasse com tal ato, motivo pelo qual foi encaminhada a descrição do pleito à $5^{\circ}$ Promotoria de Justiça da cidade de Caldas Novas/GO, com solicitação de parecer favorável sobre a referida doação do imóvel.

Furnas suspendeu as reintegrações de posse, realizando a doação das áreas das 19 famílias ao Estado de Goiás repassando às referidas áreas as famílias. O processo encontra-se na sede de Furnas no Rio de Janeiro para os procedimentos finais de doação.

Conforme o diagnóstico social realizado pela equipe técnica multidisciplinar, foi detectada a urgência do ato de regularização fundiária local, fazendo jus ao arcabouço legal para a doação dos lotes ocupados por estes no Parque das Brisas em Caldas Novas/GO, evitando, desta forma, um grave problema de ordem social com o desalojamento das famílias que ali fixaram moradia e não tendo outro local para estabelecer residência.

Realizou-se a regularização fundiária do local, desse modo cumprindo o princípio da lei federal 11.124 de 16/06/2005 que dispõe sobre o Sistema Nacional de Habitação de Interesse Social (SNHIS), cria o Fundo Nacional de Habitação de Interesse Social (FNHIS), também institui o Conselho Gestor de FNHIS. Um dos princípios são a compatibilização e integração das políticas habitacionais federal, estadual, do Distrito Federal e municipal, bem como das demais políticas setoriais de desenvolvimento urbano, ambientais e de inclusão social, ainda oferecer moradia digna como direito e vetor de inclusão social; aplicar a função social da propriedade urbana visando a garantir atuação direcionada a coibir a especulação imobiliária e permitir o acesso à terra urbana e ao pleno desenvolvimento das funções sociais da cidade e da propriedade (BRASIL, 2005).

Como a Política Nacional de Habitação, esclareceu sobre o reconhecimento de novas necessidades, por conseguinte, descortina soluções institucionais e operacionais de diferentes naturezas, fez-se necessária a criação de um sistema específico com a participação do Estado de Goiás e do Município de Caldas Novas para uma ação integrada na solução da inadequada situação habitacional.

A partir da demanda apresentada, o Estado de Goiás se posicionou à questão, indicando a necessidade de ampliar e diversificar os programas e ações no âmbito do Estado e a importância de aprimoramento contínuo de planejamento e gestão 
habitacionais, atribuídos nesse Governo à Secretaria das Cidades, sendo a AGEHAB a instância executora. Na história da política habitacional, o Estado de Goiás busca inovar e responder às pressões e demandas existentes.

Um dos objetivos do SNHIS é viabilizar para a população de menor renda o acesso à terra urbanizada e à habitação digna e sustentável; implementar políticas e programas de investimentos e subsídios, promovendo e viabilizando o acesso à habitação voltada à população de menor renda e articular (BRASIL, 2005). Desse modo, o Estado de Goiás implementou e fortaleceu dois programas: um dedicado à regularização fundiária definido como Programa Casa Legal e outro na linha da construção, reforma e ampliação de unidades habitacionais que é o Programa Habitacional Morada Nova. Ambos são iniciativas basilares para a solução dos problemas, mas que não abrangem todo o conjunto de ações necessárias ao tratamento da questão habitacional.

O programa Casa Legal é uma referência nacional em regularização fundiária, este é executado pela AGEHAB desde 2011 conquistando vários prêmios nacionais, sendo integrante do Plano de Ação Integrada de Desenvolvimento (PAI), com selo de prioridade de Governo (Goiás agora, 2017).

O decreto $\mathrm{n}^{\circ}$ 7.419, de 11 de agosto de 2011, dispõe sobre o Programa Habitacional Morada Nova, conforme esse decreto, as pessoas físicas interessadas no Programa deverão cadastrar-se mediante o preenchimento de ficha própria da AGEHAB, pois somente serão selecionados pelo Programa os beneficiários devidamente cadastrados (BRASIL, 2011).

Urge dar nas políticas habitacionais a garantia de acessibilidade para as famílias que se encontram em situação de vulnerabilidade social, caso das famílias do Parque das Brisas em Caldas Novas/GO, garantindo assim, acesso a uma condição de vida digna, com moradia e condições de trabalho. As famílias em condições de desvantagem devem ter acesso pleno e sustentável aos recursos adequados para o acesso a uma unidade habitacional de interesse social.

\section{Conclusão}

Diante de todas as etapas executadas no processo interventivo percebe-se que, a construção da esfera pública requer novas modalidades de relação entre o Estado e a sociedade civil que vão além da forma estatal, onde o público é associado ao Estado e o privado ao mercado, referendando-se ao reconhecimento do direito de todos que estejam dispostos a participar na vida pública, promovendo visibilidade e transparência pública aos envolvidos na construção de metodologias legais assertivas frente às demandas.

Cabe então à jurisprudência estabelecer a aceitação desse princípio para cumprimento da função social da propriedade, o que pôde ser demonstrado com a efetiva participação das entidades, organismos legais e parceiros na execução de uma conduta equivalente ao disposto na área de intervenção de Regularização Fundiária.

Conclui-se que, toda propriedade, sem exceção, respeitando o direito do proprietário, deve cumprir sua função social. Percebeu-se que, quando há a integração de interesses entre o público e o privado, o ordenamento jurídico determina a proibição do uso abusivo da propriedade, exercendo assim, o acesso à melhoria de qualidade de vida de um grupo de famílias que luta em prol da sustentabilidade e exercício pleno da cidadania, o que foi presenciado na realidade prática ocorrida no bairro Parque das Brisas, município de Caldas Novas/GO.

A partir da participação dos moradores locais no processo de implementação, a função social foi efetivada dentro dos arcabouços legais, absorvida pelo legislador constituinte, através do Comitê Estadual para o Monitoramento e Resolução de Conflitos Fundiários Rurais e Urbanos.

Apesar da experiência exitosa em Caldas Novas/GO, ainda existem vários processos da mesma temática pelo Brasil, evidenciando-se a falha dos agentes promotores na busca por soluções que atendam às necessidades emergenciais da sociedade, no quesito regularização fundiária, considerando as causas principais das desigualdades sociais em que se encontram as famílias em situação de posse e risco em nível nacional. 
Sugerimos que novos estudos para apontar as limitações e os resultados efetivos a respeito de outras experiências locais de regularização fundiária que ocorreram no país, considerando que essa uma política pública de relevante interesse social, e que coaduna com o direito humano fundamental de moradia. Além disso, novos estudos podem sugerir uma avaliação da política pública de regularização fundiária, seus impactos, suas limitações políticas e possíveis avanços para melhor implementação desse tipo de política pública.

\section{Referências}

Agehab. (2017) Goiás Estado Inovador. http://www.agehab.go.gov.br/.

Alonso Freire Chryssocheris. (2017) Qual diferença entre escritura e registro. https://afcadvogados.com.br/qual-diferenca-entre-escritura-e-registro/.

Amadei, V. C; Amadei, V. A. (2014) Como Lotear uma gleba - O parcelamento do solo urbano em seus aspectos essenciais (Loteamento e Desmembramento). Campinas: Millenium.

Anitelli, F; Tramontano, M. (2016) Abordagens incomuns na política habitacional brasileira: Reabilitação de edifícios ociosos e sua conversão em habitação de interesse social. Cidades, Comunidades e Territórios, Vol. 32, Jun, pp. 40 - 50.

Battaus, D. M. A .; Oliveira, E.A.B. (2016) O direito à cidade: urbanização excludente e a política urbana brasileira, Lua Nova: Revista de Cultura e Política. São Paulo, nº 97, jan/abr, p.81-106.

Bassul, J. R. (2002) Reforma Urbana e Estatuto das Cidades. EURE, Santiago, V. 28, N.84.

Brasil. Constituição da República Federativa do Brasil de 1988. Presidência da República. Casa Civil, Brasília, Outubro, 1988.

Brasil. Estatuto da Cidade. Lei 10.257, 10 de julho de 2001. http://www.planalto.gov.br/ccivil_03/leis/LEIS_2001/L10257.htm.

Brasil. Lei no 11.124, 16 de junho de 2005. http://www.planalto.gov.br/ccivil_03/_ato2004-2006/2005/lei/111124.htm.

Collis, J.; Hussey, R. (2005). Pesquisa em administração - Um guia prático para alunos de graduação e pós graduação. Porto Alegre: Bookman.

Cresswell, J. W. (2007). Projeto de Pesquisa - Métodos Qualitativo, quantitativo e misto. São Paulo: Artmed Editora.

Fonseca, M. D. C. A.; Herek, Silva. (2017) Reintegração de posse: de sua origem a sua aplicação. Revista Âmbito Jurídico. Ano XX, nº 156, jan.

Furnas (2021). Informações sobre a Usina de Corumbá. https://www.furnas.com.br/corumba/?culture=pt

Goiás. Decreto n 7.419 , de 11 de agosto de 2011. Governo do Estado de Goiás. Secretaria do Estado da Casa Civil, 12.08.2011.

http://www.gabinetecivil.goias.gov.br/decretos/numerados/2011/decreto_7419.htm.

Goiás. Lei n ${ }^{\circ}$ 17.545, de 11 de janeiro de 2012. Assembleia Legislativa do Estado de Goiás.

http://www.gabinetecivil.goias.gov.br/leis_ordinarias/2012/lei_17545.htm

Goiás Agora. http://www.goiasagora.go.gov.br/casa-legal-agehab-inicia-cadastramento-de-familias-para-processo-de-regularizacao-do-jardim-dom-fernandoi-e-ii/.

Gonçalves, R. S. (2009) Repensar a regularização fundiária como política de integração socioespacial. Estudos Avançados. Vol. 23 Ed. (66).

IBGE, Instituto Brasileiro Geográfica e Estatística. http://ibge.gov.br/cidadesat/xtras/perfil.php?lang=\&codmun=520450.

Júnior. A. R. S; Vale, N. K. A; Wander, A. E. (2016) Boletim Conjuntura Econômica Goiana. Instituto Mauro Borges, SEGPLAN. Modernização Agrícola e o êxodo rural entre 1960 e 2010 no Estado de Goiás, nº 36, mar, 2016.

Oliveira, E. A.; Silva Costa, M. R. (2016) O processo de ocupação do solo urbano e a política habitacional em Goiânia/Goiás (1933-2010). Revista Brasileira de Assunto Regionais e Urbanos. Vol.2, n. 01, p.151-167, jan/jun.

Nunes, M. A. C.; Júnior, C. M. A. F. (2018) Regularização Fundiária Urbana: Estudo de caso do bairro Nova Conquista, São Mateus - ES. Revista Direito da Cidade. vol. $10, \mathrm{n}^{\circ} 2$.

Sousa, S. P.; Peres, V.N.; Martins, R. P. (2009) Turismo e o uso das águas termais Caldas Novas (GO) - Brasil. In: $12^{\circ}$ Encontro De Geográfos Das América Latina - Egal, Montevideo - Uruguai. Anais. Caminando en una América Latina en transformación.

Vieira, E. G.; Junior, O. C. R. (2014) A regularização fundiária urbana de interesse social em áreas de preservação permanente à luz do direito fundamental ao meio ambiente ecologicamente equilibrado no Brasil. In: XXIII Congresso Nacional do Conpedi, João Pessoa, Apresentação: UFPB, Conpedi, p.167-196.

Yin, R. (2015) Estudo de Caso - Planejamento e Métodos. Porto Alegre: Bookman. 